\section{AB0381 VALIDATING DRAFT DCVAS CRITERIA IN A SINGLE CENTER GCA COHORT IN SOUTHERN NORWAY}

P. Andel ${ }^{1,2,3}$, S. Brådland ${ }^{3}$, A. Diamandopoulos ${ }^{4,5}$, G. Myklebust $^{3}$, G. Haugeberg ${ }^{3,6} .{ }^{1}$ Østfold Hospital Trust, Department of Cardiology, Kalnes, Norway; ${ }^{2}$ University of Oslo, Department of Clinical Medicine, Oslo, Norway; ${ }^{3}$ Hospital of Southern Norway, Department of Rheumatology, Kristiansand, Norway; ${ }^{4}$ Akershus University Hospital, Department of Rheumatology, Oslo, Norway; ${ }^{5}$ Martina Hansens Hospital, Department of Rheumatology, Kristiansand, Norway; ${ }^{6}$ Norwegian University of Science and Technology, Department of Neuromedicine and Movement Science, Faculty of Medicine and Health Sciences, Trondheim, Norway

Background: Giant cell arteritis (GCA) is the most common medium- and large vessel vasculitis in the elderly population. The diagnostic algorithm has changed in recent years in many institutions from temporal artery biopsy (TAB) to imaging based diagnosis (1). However, classification criteria that relied on TAB remained unchanged since 1990 (2). Reflecting the recent change in practice the Diagnostic and Classification Criteria for Vasculitis Study (DCVAS) group presented a draft classification criteria set for GCA. Endorsement by major scientific societies is currently pending (3).

Objectives: To test the accordance of the GCA cohort of a single center in southern Norway between 2006 and 2018 to the draft DCVAS classification criteria in GCA.

Methods: All patients diagnosed with GCA between 2006 and 2018 in our clinic were identified by international classification of disease (ICD) code for GCA (m31.5/m31.6) in the local electronic database. The draft DCVAS classification criteria were applied to all patients at the time of diagnosis, irrespective of the algorithm used to diagnose GCA. In the draft DCVAS classification criteria a score of 6 would be necessary to classify a patient as having GCA.

Results: A total of 77 patients (55 female) diagnosed with GCA in the defined timespan were identified. Mean age was 69.2 years ( $57-83$ years). As all patients were diagnosed with vasculitis and were older than 40 years of age, all patients met the compulsory criteria. The table 1 below shows the absolute number of patients that fulfilled the single criteria.

The number of patients fulfilling the draft DCVAS classification criteria was 75 $(97.4 \%)$. In the female cohort $96.4 \%$ patients finally diagnosed with GCA would be classified as having GCA as would $100 \%$ in the male cohort.

Mean score was 12.4 (range $3-25$ ). In $33.3 \%$ of patients imaging was critical for classification. Laboratory findings were critical for classification in $9.3 \%$, head ache and scalp tenderness in 5.3\%, temporal artery biopsy, morning stiffness and jaw claudication in $2.7 \%$. The differentiation in possible and definite vasculitis in TAB did not change the result in any patient. Neither did sight-loss contribute to classify any patient. Five patients $(6.5 \%)$ were diagnosed on clinical features and laboratory findings alone. Thirteen patients diagnosed with GCA and fulfilling DCVAS criteria had negative biopsies, three patients had an inconclusive TAB. Mean arterial biopsy length was $9 \mathrm{~mm}$.

Table 1.

\begin{tabular}{lcc}
\hline $\begin{array}{l}\text { Draft DCVAS classification } \\
\text { criteria }\end{array}$ & $\begin{array}{c}\text { Aboslute } \\
\text { number }\end{array}$ \\
\hline Age>40 years and vasculitis diagnosis (compulsatory) & 77 \\
New temporal headache & +2 & 48 \\
Scalp tenderness & +2 & 21 \\
Sudden visual loss & +2 & 2 \\
Morning stiffness shoulder/neck & +2 & 34 \\
Jaw claudication & +2 & 22 \\
ESR $>50$ mm/h or CRP > 10 mg/l & +3 & 72 \\
TAB showing possible vasculitis & +3 & 8 \\
TAB showing definite vasculitis & +5 & 16 \\
Halo sign & +5 & 61 \\
Bilateral axillary involvement & +3 & 25 \\
PET showing aortitis & +3 & 4 \\
\hline
\end{tabular}

Conclusion: A high percentage $(97.4 \%)$ of the patients diagnosed with GCA in our cohort fulfilled the draft DCVAS classification criteria. The high mean score (12.4) showed that DCVAS criteria did not depend heavily on single criteria. As diagnosis in our cohort was mainly based on ultrasound, imaging was the most critical item. This might be desirable as clinical features and laboratory markers should in general be confirmed by either imaging or TAB to ascertain diagnosis. However, five patients were solely diagnosed on clinical features and laboratory markers. Sight-loss did not contribute to classification in our cohort as most patients were seen in a fast-track clinic (FTC), but might be valuable in cohorts without FTC.

\section{REFERENCES:}

[1] Dejaco C et al, Ann Rheum Dis. 2018;77(5):636-643

[2] Hunder GG et al, Arthritis Rheum. 1990 Aug;33(8):1122-8

[3] Merkel PA: oral presentation, American College of Rheumatology Annual Meeting 2018: October 19-24; 2018

Disclosure of Interests: None declared

DOI: 10.1136/annrheumdis-2021-eular.4128

\section{AB0382 DOES THE ULTRASOUND IMAGE OF THE LARGE VESSEL WALLS DIFFER IN THE SUBTYPES OF GCA AND PMR OR THERE IS A SYSTEMIC SUBCLINICAL COMMON INFLAMMATION?}

E. Fernández-Fernández ${ }^{1}$, I. González-Mazón ${ }^{2}$, I. Monjo ${ }^{1}$, J. M. Mostaza ${ }^{3}$, C. Lahoz ${ }^{3}$, E. De Miguel' ${ }^{1}{ }^{1}$ La Paz University Hospital, Rheumatology, Madrid, Spain; ${ }^{2}$ Marqués de Valdecilla University Hospital, Rheumatology, Santander, Spain; ${ }^{3}$ Carlos III Hospital, Internal Medicine, Madrid,

Spain

Background: Several clinical patterns of giant cell arteritis (GCA) have been described including cranial GCA (c-GCA), large vessel GCA (LV-GCA), mixed forms of C-GCA and LV-GCA (mixed-GCA), and even polymyalgia rheumatica (PMR) that has been associated with GCA and some degree of subclinical vascular inflammation could be present in the patients. However, many questions about this disease and its subtypes remain unanswered.

Objectives: To investigate the affectation of the arterial wall of GCA and its subtypes and PMR and to know if there really are different ultrasound patterns that can be determined or if otherwise they present a common subclinical systemic inflammation with only different degrees of involvement of the vascular wall.

Methods: All available ultrasound examinations of patients referred to our fast-track GCA clinic for suspected GCA in the last three years were reviewed and retrospectively collected data. Patients who had undergone ultrasound examination of both cranial and large vessels (axillary, subclavian and carotid arteries) were included. The videos and images of the large vessels of each patient were reviewed and intima-media thickness (IMT) and hypoechoic halo measurements were taken. The data of the following groups, established according to the final diagnosis confirmed by the doctor after a follow-up between six months and three years, were compared: GCA group (within it 3 other groups were included: c-GCA, LV-GCA and mixed-GCA), PMR group and the group without ACG or PMR (nonGCA).

Results: We analyzed the examinations of 300 patients and 161 baseline examinations were included: 76 with GCA (32 c-GCA, 14 LV-GCA and 30 mixed-GCA), 29 with PMR and 56 non-GCA. The mean IMT for each large vessel explored and the statistical significance between the different groups

Table 1. Ultrasound IMT and halo measures in the different subtypes of GCA, PMR and controls

\begin{tabular}{|c|c|c|c|c|c|c|c|}
\hline Arteries & $\begin{array}{c}\text { Non-GCA } \\
n=56\end{array}$ & $\begin{array}{l}\text { GCA } \\
n=76\end{array}$ & $\begin{array}{c}\mathrm{c}-\mathrm{GCA} \\
\mathrm{n}=32\end{array}$ & $\begin{array}{c}\text { LV-GCA } \\
n=14\end{array}$ & $\begin{array}{l}\text { Mixed- } \\
\text { GCA } n=30\end{array}$ & $\begin{array}{l}\text { PMR } \\
n=29\end{array}$ & $p<0.05$ \\
\hline $\begin{array}{l}\text { Right axillary } \\
\qquad(\text { mean } \pm \text { SD) }\end{array}$ & $0.67 \pm 0.19$ & $0.95 \pm 0.30$ & $0.75 \pm 0.20$ & $1.03 \pm 0.33$ & $1.11 \pm 0.27$ & $0.65 \pm 0.13$ & $\begin{array}{c}2^{\star}, 3^{*} \\
4^{\star}, 5^{\star}, 6 \\
7^{*}, 8^{\star}\end{array}$ \\
\hline $\begin{array}{l}\text { Left axillary } \\
\text { (mean } \pm \text { SD) }\end{array}$ & $0.61 \pm 0.12$ & $0.92 \pm 0.29$ & $0.77 \pm 0.19$ & $0.99 \pm 0.25$ & $1.03 \pm 0.33$ & $0.66 \pm 0.13$ & $\begin{array}{c}1^{\star}, 2^{\star}, 3^{\star} \\
4,5^{\star}, 6 \\
7^{\star}, 8^{\star}\end{array}$ \\
\hline $\begin{array}{l}\text { Right } \\
\text { subclavian } \\
\text { (mean } \pm \text { SD) }\end{array}$ & $0.70 \pm 0.15$ & $1.00 \pm 0.31$ & $0.79 \pm 0.16$ & $1.09 \pm 0.36$ & $1.10 \pm 0.29$ & $0.70 \pm 0.20$ & $\begin{array}{l}2^{\star}, 3^{\star}, 4^{\star} \\
5^{\star}, 7^{\star}, 8^{\star}\end{array}$ \\
\hline $\begin{array}{l}\text { Left Subclavian } \\
\text { (mean } \pm \text { SD) }\end{array}$ & $0.62 \pm 0.14$ & $0.95 \pm 0.27$ & $0.76 \pm 0.16$ & $1.05 \pm 0.25$ & $1.06 \pm 0.26$ & $0.64 \pm 0.18$ & $\begin{array}{c}1^{*}, 2^{*}, 3^{*} \\
4^{*}, 5^{*} \\
7^{\star}, 8^{\star}\end{array}$ \\
\hline $\begin{array}{l}\text { Right CCD } \\
(\text { mean } \pm \text { SD) }\end{array}$ & $0.79 \pm 0.22$ & $0.97 \pm 0.26$ & $0.99 \pm 0.22$ & $0.91 \pm 0.29$ & $1.05 \pm 0.28$ & $0.81 \pm 0.10$ & $\begin{array}{l}1^{*}, 3^{*} \\
6^{*}, 8^{*}\end{array}$ \\
\hline $\begin{array}{l}\text { Left CCD } \\
\text { (mean } \pm \text { SD) }\end{array}$ & $0.81 \pm 0.16$ & $0.99 \pm 0.22$ & $0.95 \pm 0.20$ & $0.97 \pm 0.17$ & $1.03 \pm 0.27$ & $0.82 \pm 0.20$ & $1,2,3^{*}, 8$ \\
\hline
\end{tabular}

SD: Standard deviation; CCD: common distal carotid artery.1=c-GCA vs non-GCA $2=\mathrm{LV}-\mathrm{GCA}$ vs non-GCA; $3=$ mixed-GCA vs non-GCA; $4=\mathrm{C}-\mathrm{GCA}$ vs LV-GCA; $5=\mathrm{C}-\mathrm{GCA}$ vs mixed-GCA; $6=P M R$ vs $c-G C A ; 7=P M R$ vs LV-GCA; $8=P M R$ vs mixed-GCA; ${ }^{*} p<0.01$. 
are shown in Table 1. All arteries except the carotid arteries had a significantly higher IMT in the LV-GCA and mixed-GCA groups when compared with both C-GCA and non-GCA groups. There were no differences in IMT between mixed-GCA and LV-GCA. There were also no differences in any explored artery between PMR and non-GCA. There were statistically significant differences in the IMT of the bilateral axillary and subclavian arteries between the PMR group and all the GCA subtypes, being greater in the latter. IMT tended to be higher in the C-GCA group when compared to non-GCA, reaching statistical significance in the left arteries (axillary, subclavian, and distal carotid). Although there was also a tendency for IMT to be higher in mixedGCA patients than in LV-GCA patients, the differences did not reach statistical significance.

Conclusion: Large vessel ultrasound does not differ between healthy patients and those with PMR without confirmed GCA. Our data suggest that mixed-GCA subtype is not an intermediate form between the cranial and LV-GCA suptypes but could have a higher inflammatory burden.

Disclosure of Interests: Elisa Fernández-Fernández: None declared, Iñigo González-Mazón: None declared, Irene Monjo Speakers bureau: Roche, Novartis, UCB, Gedeon Richter, Consultant of: Roche, José María Mostaza: None declared, Carlos Lahoz: None declared, Eugenio de Miguel Speakers bureau: AbbVie, Novartis, Pfizer, MSD, BMS, UCB, Roche, Grunental, Janssen, Sanofi, Paid instructor for: Janssen, Novartis, Roche, Consultant of: AbbVie, Novartis, Pfizer, Galapagos, Grant/research support from: Abbvie, Novartis, Pfizer

DOI: 10.1136/annrheumdis-2021-eular.4134

\section{AB0383 OCULAR MANIFESTATIONS DURING GIANT CELL ARTERITIS}

A. Mzabi ${ }^{1}$, N. Adaily ${ }^{1}$, L. Ines ${ }^{1}$, I. Ben Hassine ${ }^{1}$, J. Anoun ${ }^{1}$, M. Karmani ${ }^{1}$, F. Ben Fredj ${ }^{1}$, C. Laouani ${ }^{1}{ }^{1}$ University Hospital Center of Sahloul, Internal Medicine, Sousse, Tunisia

Background: Horton's disease (HD) or giant cell arteritis (GCA) is a segmental and plurifocal giant cell inflammatory panarteritis, predominant in large and medium sized vessels. Ocular damage during giant cell arteritis is frequent and is considered the most serious damage, possibly causing blindness in $15 \%$ of cases in recent series (1).

Objectives: Describe the different ophthalmological manifestations during GCA.

Methods: This is a retrospective monocentric descriptive study of 19 files of subjects diagnosed with $\mathrm{HD}$, hospitalized in the internal medicine department of de Sousse between January 2000 and December 2020.

Results: The average age of patients at diagnosis was 70 years, with extremes of 53 and 92 years. There were 14 females $(71.4 \%)$ and 5 males $(28.6 \%)$. Ophthalmologic manifestations were present in 13 patients $(71 \%), 6$ of whom were female.

Decreased visual acuity was reported in 8 cases (58.33\%) with biolateral blindness in one case, visual blur in 9 cases $(75 \%)$, eye pain in two cases.

Ophthalmological examination was normal in 8 cases $(42 \%)$. A decrease in visual acuity was objective in 4 cases $(21 \%)$. One case of nodular episcleritis was noted. The fundus showed anterior ischemic optic neuropathy in 2 cases $(10.5 \%)$ and left optic atrophy in another case. A visual field was performed in 2 cases showing associated retrobulbar optic neuritis. Therapeutically, Methylprednisolone boli were prescribed in patients with anterior ischemic optic neuropathy, followed by oral corticosteroid therapy at a dose of $1 \mathrm{mg} / \mathrm{kg} / \mathrm{day}$. A dose of $0.7 \mathrm{mg} / \mathrm{kg} /$ day of prednisone was prescribed in the other cases. Blindness was irreversible.

Conclusion: The most common eye diseases in HD are acute anterior ischemic optic neuritis, retinal artery occlusion and posterior ischemic optic neuropathy. Episcleritis is a rare ophthalmologic manifestation of this vasculitis (2). More exceptionally, Horton's disease may cause NORB by affecting the vessels that supply the optic nerve $(<5 \%$ of cases $)(3,4)$. In our series of studies, acute anterior ischemic optic neuritis was less observed than in the literature. This is probably due to the reduced number of patients.

\section{REFERENCES:}

[1] M.Khedher. I.Rachdi. Z.Aydi. F.Daoud. B.Ben Dhaou. F.Boussema. Eye damage during Horton's disease: about 42 cases. La Revue de Médecine Interne 2017; 38:115

[2] Rim Klii. Wafa Chebbi. Nodular episcleritis: an unusual inaugural manifestation of Horton's disease. Pan Afr Med J 2015; 21: 20.

[3] M.Essouril.RachdiF.DaoudZ.AydiH.ZoubeidiB.Ben Dhaou et al. Retrobulbar Optic Neuropathy in Internal Medicine. La Revue de Médecine Interne 2018; 39: 132.

[4] M A González-Gay, C García-Porrúa, J Llorca, A H Hajeer, F Brañas, A Dababneh et al. Visual manifestations of giant cell arteritis. Trends and clinical spectrum in 161 patients. Medicine (Baltimore) 2000;79(5): 283-92.

Disclosure of Interests: None declared

DOI: 10.1136/annrheumdis-2021-eular.4143

\section{\begin{tabular}{|l|l}
\hline AB0384 IMPACT OF TEMPORAL ARTERY ULTRASOUND \\
\hline
\end{tabular} ON SURVIVAL OF PATIENTS WITH GIANT CELL ARTERITIS}

P. Estrada ${ }^{1}$, D. Reina ${ }^{1}$, V. Navarro ${ }^{1}$, O. Camacho ${ }^{1}$, D. Cerda ${ }^{1}$, D. Roig Vilaseca ${ }^{1}$, S. Heredia ${ }^{1}, \mathrm{H}$. Corominas ${ }^{2} .{ }^{1}$ Hospital de Sant Joan Despí Mois ès Broggi, Rheumatology, Sant Joan Despí, Spain; ${ }^{2}$ Hospital de la Santa Creu i Sant Pau, Rheumatology, Barcelona, Spain

Background: Giant cell arteritis (GCA) is the most common primary systemic vasculitis in adults over 50 years of age. Its incidence increases with age, with a peak between $70-80$ years and predominates in women, 3:1. It is a medical emergency that, if not diagnosed, can lead to irreversible complications. The delay in time from diagnosis to start of treatment is crucial to avoid possible serious outcomes on short, medium and long term. Survival in GCA is estimated between $60-90 \%$ at 5 years and $48-81 \%$ at 10 years. Efforts have been made to implement rapid diagnostic circuits to assess patients and initiate treatment without delay with good results both in reducing permanent vision loss and in reducing the costs of these patients due to emergency visits and admissions. The morbidity and mortality of this disease is high, but the use of efficient diagnostic strategies, such as ultrasound of superficial temporal arteries, has proven to be a useful, practical, cost-effective and, above all, quick tool to make the diagnostic approach.

Objectives: Analyze the impact of early temporal artery ultrasound on survival for patients with GCA.

Methods: Survival study of 48 patients with GCA, in two different "stages" in terms of diagnostic approach: Group A $(n=27)$, patients diagnosed between 2002 - 2011 using only ACR 1990 criteria and Group $E(n=21)$ diagnosed between 2010-2015 using ACR criteria and TAUS. TAUS was performed by Rheumatologists with extensive experience in ultrasound and within a period of no more than 7 days for these patients. The definitive diagnosis of GCA was based on the clinical criteria of the Rheumatologist within the clinical and analytical context and with the specific complementary examinations for each case (Ultrasound, PET-CT, biopsy). Demographic data, comorbidities, signs and symptoms at debut, analytical data, complementary examinations, treatment and evolution were obtained retrospectively through the electronic medical record of the patient, based on the database of our GCA cohort. A survival analysis was performed considering death as the main outcome. The statistic used was the Kaplan-Meier test. In addition, other complications related to treatment or pathology are collected.

Results: The mean age at diagnosis of our patients was $79+-6$ years, with a female: male ratio of $3: 1$. The follow-up was between 2 and 16 years with a mean of $5.8+-3$ years, until the last visit collected or until the outcome of death. Group A had a survival at 5 and 10 years of $53.4 \%$ and $36.7 \%$ respectively, while group E of $79.5 \%$ at both cut-off points. (Figure 1 ).

There is a significant difference between the survival of both groups, $p$ $<0.01$, this being better in the group in which TAUS was implemented for rapid diagnosis (group $\mathrm{E}$ ). The main causes of death were cardiovascular 